\title{
Husband-wife Roles as a Correlate of Contraceptive and Fertility Behaviour
}

\author{
MUHAMMAD IQBAL ZAFAR
}

In this paper, an investigation of reproductive behaviour within the socioeconomic and cultural frameworks is carried out to find the extent to which socioeconomic, cultural, and attitudinal variables (such as husband and wife's education, family income, husband's occupation, child mortality, exposure to the mass media, and husbandand-wife relationship in terms of egalitarian roles, role-segregation, husband's authority, and domination in family and non-family decisions) influence the fertility decision-making process.

The quantitative and qualitative techniques are used for exploring the respondents' views regarding contraceptive and fertility behaviour. Principle Component Analysis (PCA) is applied to identify new meaningful underlying variables and to reduce the multi-dimensionality of variables. The chi-square test is employed to explore the relationships between the predictor variables and the dependent variables. Multiple linear regression is also used to establish the relative importance of each of the predictor variables.

Bivariate, multiple linear regression and qualitative analysis demonstrate that preferences for smaller families and contraceptive use were found to be consistently associated with modern attitudes and behaviour towards the husband-and-wife relationship. Family income, husband's occupation, child mortality, and age at marriage offered no explanation of the reproductive behaviour. It is concluded that cultural setting and tradition exert an important influence on reproductive behaviour independent of development in economic realities. It is suggested that for the attainment of demographicdevelopmental objectives, the issue of women's status is not incidental; it is essential. The argument is not that improvements in women's status need to be pursued only for population policy purposes, but rather that they comprise a crucial social developmental goal in their own right.

\section{INTRODUCTION}

Pakistan is at a very early stage of fertility transition and has for long experienced high stable fertility. The estimates of the population growth rate of the country range from 2.85 percent to 3.15 percent; the growth rate for 1993 was

Muhammad Iqbal Zafar is Associate Professor in the Department of Rural Sociology at the University of Agriculture, Faisalabad.

Author's Note: The author is grateful to Dr David Phillips, Director, and Elaine Davies, Programme Officer, both of the Institute of Population Studies, University of Exeter, U.K., for academic support in the preparation of this article. The author is thankful to the World Health Organisation and the Government of Pakistan for supporting this research financially. 
estimated at 2.95 percent [Government of Pakistan (1992)]. The Total Fertility Rate (TFR) during 1980s, according to various surveys, ranged from 6.0 to 6.9, and there is no agreement on the fertility level in Pakistan. The Pakistan Demographic Health Survey (PDHS) yielded TFR of 5.5 for 1985-1991 and 5.2 for 1990-91 [Government of Pakistan (1991)]. In the presence of an unimpressive rise in contraceptive use and considerable decline in length of breastfeeding (from an average of 17 months in the 1975 data from the Pakistan Fertility Survey to 11 months in the 1991 PDHS), the evidence of change in fertility seems to be unrealistic, unless contraceptive use has been severely underreported in the PDHS.

Planners and policy-makers in the Government of Pakistan have long recognised the demographic developmental problem relating to the high rate of growth and population momentum [Hashmi (1991)]. Hashmi has pointed out that substantial allocation of funds in successive Five-Years Plans with different strategies have not succeeded in making the family planning programme in the country quite effective.

Classic demographic transition theory which was originally based on the experience of the fertility transition in Western countries suggested that fertility decline was defined within the context of socio-economic development. The economic school of thought viewed the solution to rapid population growth in terms of socio-economic and industrial development. For instance, the implication drawn for population policy by some country representatives attending the World Population Conference held in Bucharest in 1974 was summed up in the slogan 'Development is the best contraceptive' and 'Look after the people and population will look after itself’ [United Nations (1974)].

Economic approach to fertility has been used to explain fertility differentials particularly over the last two decades. The economic models assume that fertility preferences are fixed and thus the fertility differentials are explained by differences in opportunities (education and work) [Becker (1981)]. The economic school is of the opinion that the utility-maximising decisions in the context of fertility are functioned by prices and income. According to financial circumstances, a household (i.e., a couple) strives for an optimal fertility choice. Economists perceive children in terms of costs, like actual expenses and foregone opportunities and benefits.

Some social scientists have questioned the statement made by the cost-benefit school of thought that structural development is a pre-condition for fertility transition for developing countries [Kirk (1971)]. Kirk has further stated that the relevance of this theory, which is based on European experience, to developing countries is doubtful because of the significant difference concerning the situations facing pre-industrial Europe and contemporary developing countries. There is a fast pace of economic development today, and modern communications, contraceptive technologies, and international assistance are available to assist developing countries 
in their demographic transition. However, the fertility levels are still persistently high in many developing countries, such as Iran, Saudi Arabia, Kuwait, and Nigeria [World Bank (1991)].

Tietelbaum (1975) points out that cultural development in terms of aspirations, attitudes, and a new code of behaviour rather than structural development appeared to be a pre-condition for fertility decline. Tietelbaum doubts the explanatory and predictive power of the theory in explaining the fertility transition in developing countries and points out that the relevance of transition theory for the present situation of developing countries is an important issue for both science and policy. He states: "From a scientific perspective, the weakness and ambiguities of transition theory in explaining European experience may be further examined if one follows the current and future demographic processes of developing countries because social and economic circumstances of modern-day Asia, Africa, and Latin America are quite different than those of the 19th-century Europe" (p. 174). Knodel et al. (1982) also find the decline in marital fertility in Thailand to be nearly simultaneous across almost all socio-economic groups.

The indirect analysis of World Fertility Survey (WFS) confirms the existence and significance of non-material forces [Freedman (1987); Cleland (1985)]. Thus Cleland sums up “.... the results are more consistent with an ideational theory of change, based on the spread of new aspirations or new attitudes towards family formation or birth control, than with a structural theory, which emphasises changes in economic roles of family units, of women, or of children” (p. 243). Contraceptive differentials are pronounced together with ethnicity in Malaysia, religion in Sri Lanka, and language between the Sudanese and the Javanese, Balinese, and Indonesians in the province of West Java in Indonesia; all are regarded as cultural indicators [Nai Peng and Abdurahman (1981); Alam and Cleland (1991); Shoeradji and Hatmadji (1982)].

The decision-making approach by the new home economists has, however, acknowledge that many non-economic factors might influence fertility behaviour, and that those factors might be included within the economic framework [Easterlin (1983)]. Some population researchers are of the opinion that marital fertility transition is conditioned by a series of intermediate variables which, in turn, are strongly influenced by economic, social, and cultural factors [Bongaarts (1978); Lesthaeghe and Wilson (1986)]. The recent analysis of Pollack and Watkins's pinpoints the significance of both socio-economic and cultural frameworks in explaining fertility differentials. They find that cultural traditions are compatible with observed behaviour, which is related to opportunities and preferences, whereas observed behaviour is generated by the diffusion of opportunities or by the diffusion of preferences (e.g., about the legitimacy of fertility regulation or the desirability of a few children) or by the coincidental diffusion of both [Pollack and Watkins (1993)]. 
In this study an attempt is made to identify the important predictor variables of fertility and contraceptive behaviour within the socio-economic and cultural frameworks. Among socio-economic dimensions, the influence of husband and wife's education, family income, husband's occupation, and child mortality on reproductive behaviour has been examined. Among cultural factors, the influence of different aspects of husband-wife relationship on fertility and contraceptive behaviour has been identified.

The literature on the husband-and-wife relationship shows its significance in the context of reproductive behaviour. It is argued that the traditional values related to sex-role exert a strong effect on couples' contraceptive behaviour in the Indian subcontinent. In the region, the husbands understand that it is their moral obligation to meet all reasonable demands of their wives and children and wives believe that satisfying their husbands and bringing up the children (including conjugal loyalty) are their functions [Ramu (1988)]. Ramu also states that by the virtue of husbands' instrumental roles, they mostly enjoy a formal and legitimate right to exercise authority in family matters. The husband's social power is assumed to be associated with the fertility decision-making process. It is viewed that in the traditional societies, social power is not due to ability; it is inherited by the family from the social system [Beckman (1983)]. Oppong (1982) states that the higher status of women and more egalitarian roles of husband and wife are related to a lower fertility and a higher level of contraceptive use. The egalitarian environment may allow women to calculate the costs and benefits of having another baby; it also eases access to contraception for women. In liberal relationships, women are more ready for social change; and to accept change in the social system.

In general, Pakistani society recognises the superior status of men to that of women. The status accorded to Pakistani women is normally through ascription. Traditionally, the Pakistani woman was given an inferior and subordinate status. Poverty, low level of education, and traditions make people even more traditionbound. It is considered that it is for the woman's own good that the man takes all the basic decisions - this helps to determine the woman's status in the society. Man defines her role in a variety of activities. Demanding from her an intensive and unquestioning loyalty, all familial and non-familial decisions are taken either by husbands or their parents. Wives are generally not allowed to take part in extrafamilial activities. The decisions about marriage, receiving proper education, securing gainful employment, receiving proper health care, or about migration are all made for her, and not by her. Mostly, the woman lives with her husband's parents, and the husband's brothers and sisters. Reproductive behaviour is shaped by the values, norms, and beliefs about childbearing prevalent in the society [Shah (1986)].

People believe that God created woman in order to stay at home, and to serve the husband and the children. Women are subject to the law of obedience which is 
the primary function of the marriage institution. It is considered a woman's duty to be obedient to her husband, to her father, and to her father-in-law. The main function of the Pakistani woman is to bear and rear children. Decisions about pregnancy, birth, contraception, and sexuality are made mainly by the husband [Shah (1986)]. These are the factors which narrow the horizon of women's familial and extrafamilial activities and suppress their reproductive independence-hence a Pakistani woman traditionally seeks social status through fertility and childbearing [Shah (1986)].

\section{OBJECTIVES OF THE STUDY}

The study was designed to investigate factors influencing fertility and contraceptive behaviour within the socio-economic and cultural frameworks in order to assist the Government of Pakistan in formulating such population policies as will promote the family planning programme and reproductive health and cause a fertility decline in the country.

\section{CONCEPTUAL FRAMEWORK}

It is evident from the discussion that the study aims to derive policy implications for the promotion of the family planning programme and small family norms within the framework of socio-cultural values-role-relationships of husband and wife and media exposure. The study is based on three sets of variables: (a) background variables-socio-economic and demographic conditions, (b) cultural variables-role-relationships and exposure, and (c) dependent variablescontraceptive and fertility behaviour.

The socio-economic and demographic variables provide a description of the respondents selected for the study and the socio-cultural characteristics of users and non-users identified by reference to the main study variables. This category measures the influence of husband and wife's education, family income, and husband's occupation, age at marriage, and number of children dead on contraceptive behaviour.

The 'role-relationships and exposure' variables (independent) assess the effect of different domestic and social dimensions on contraceptive behaviour which include wife's contact with mass media, wife's help (by husband) around the house, wife's attitudes towards husband domination in taking decisions about family matters, the degree of husband's permissiveness (permission for wife to prepare herself for and to participate in recreational activities such as going out to watch movies at the cinema and attending parties), sex segregation roles (opinion of women about the labour roles of men and women).

The family size performance measured by Coombs's IN Scale is also used as a dependent variable in the study. The measure is based on the conjoint measurement 
and the unfolding theory of preferential choice. The position of respondents is located on the IN continuum scales by asking a series of questions about family size preferences. The places of individuals on the IN psychological scales ranged from IN 1 (a preference for a small family) to IN 7 (a preference for a large family). The higher the IN value, the greater the potential for large families. The IN scale provides the pure measure of family size preferences independent of the influence of sex preference. The measure represents an underlying preference structure or bias which has been identified to be more predictive of fertility behaviour than a single valued first preference, because every question involved in this approach to assess the family size preference was not arbitrarily chosen, but was based on the measurementtheoretic approach [Coombs (1976); Coombs and Sun (1978)].

The linkages between beliefs and values, fertility, and contraceptive behaviour are outlined in the conceptual framework given in Figure 1. In this study, family size preference is treated as the main outcome of reproductive behaviour.

\section{Study Design and Sampling Procedure}

A comparative study was carried out to assess the effects of the variables under study on contraceptive behaviour. Two groups of women, contraceptive-users and non-users, were selected from two major cities of Pakistan, Lahore and Faisalabad. The users group comprised fecund women (having at least one birth in the last five years) of age 25 years and more, with at least two living children, who were using any method of modern contraception (excluding sterilisation) two months to the date of interview and living with their husbands. The non-users group had characteristics (age, number of living children, and residence) similar to those of the users of modern methods but were not using any method of contraception. Pregnant women were excluded to ensure the comparability of the groups.

A multi-stage cluster, systematic sampling design is used. Three localities which had family planning clinics or family welfare centres or both were randomly selected from each city and a required number of bazaars (main streets-treated as clusters) were selected at random from each of the localities by taking into account the number of households in the bazaars to provide the basic sampling frame. 350 non-users of any method were interviewed, having been identified through systematic random sampling from each of the cities. Three family planning clinics situated in the selected localities from each city were approached to interview users of modern methods. As the use rate of modern methods of contraception in Pakistan is low, the other, 200 current users of modern methods were identified for interviewing from the family planning clinics and the family welfare centres in each area. Therefore, the total sample size of users of modern methods and non-users of any method from both of cities is 1100 . 
Independent Variables

Dependent Variables

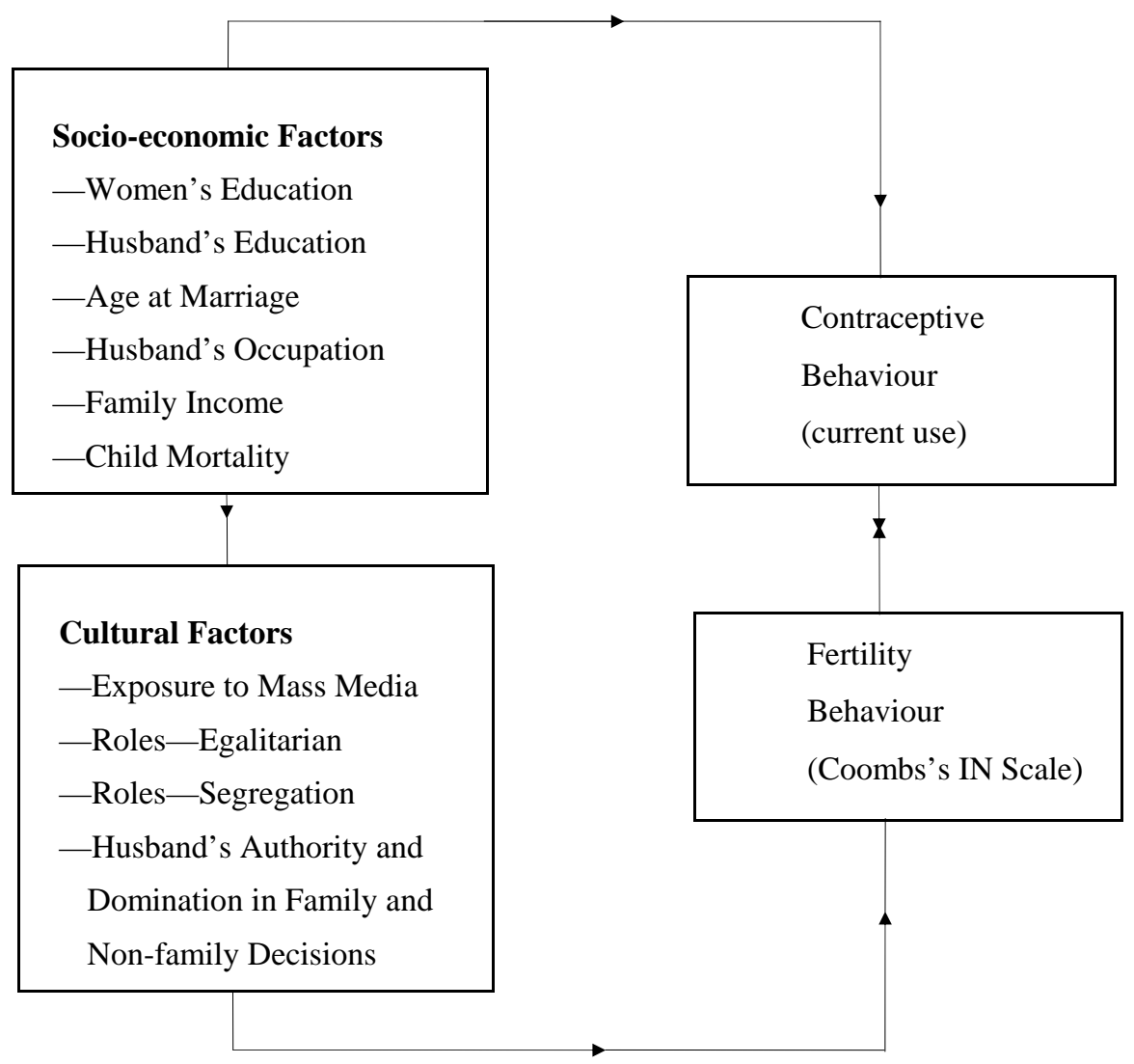

Conditional Variables

Age: Women of age 25-45 years. Residence: Women from Cities (urban area). Parity: Women with at least two living children.

Fig. 1. Conceptual Framework Showing the Inter-relationships among Sociocultural Variables and Fertility and Contraceptive Behaviour. 
A qualitative study was also conducted to have an insight into the perceptions of respondents about family life and contraceptive use. It is argued that the joint application of quantitative and qualitative techniques in family planning research offers better understanding of people's views about reproductive and contraceptive behaviour than a single approach [Knodel et al. (1984); Schearer (1983)]. It was likely that reproductive and contraceptive behaviour of users of modern methods and non-users of any method would be different. So separate focus group discussions were arranged for non-users and users, with a slight change in the interviewing schedule selected for discussion. There were two groups of users of modern methods (excluding sterilisation) from each city (Lahore and Faisalabad), and two groups of non-users of any method, one group from each of these cities.

\section{Analysis Plan}

Although maximum care is taken to develop statements in a scale to measure the single idea, yet Gronbach's alpha and Principal Component Analysis procedure are also used to identify the questions (statements) which measure the same idea. Gronbach's alpha does not meet the required criterion (reliability coefficient should be 0.80 or above) because the coefficients produced by Gronbach's alpha are within the range (0.65 to 0.75$)$ for different scales indicating items in the scales representing more than one idea. Under these conditions, the preferred analytical procedure is Factor Analysis-Principal Component Analysis (PCA).

PCA is applied to achieve two objectives. The first objective is to assess the degree to which individual items or statements address the same concept. The items or statements which are internally consistent or represent the same idea are then grouped into a single variable known as an index variable, considered to be a more reliable indicator of the behaviour being investigated than is a measure (attitude) based on the response to a single attitudinal question [Nachmias and Nachmias (1981)]. The second objective of the PCA is to determine the degree to which the variables can be reduced to a smaller set. Briefly, PCA is applied to identify new meaningful underlying variables and to reduce the multi-dimensionality of variables. It is important to mention that the lowest scores on the scale represent extreme traditionalism, and the highest scores extreme modernism.

\section{Index Scores}

The co-efficients, i.e., loading factors, which indicate how much weight is given to each factor, have been obtained. A high value of factor loadings (coefficients) of the variables is an indication of their high correlation with the factor under which the variables are identified. The factors are estimated using the coefficients and the observed variables (items). The score for the $j$ th factor for case $k$ is estimated as: 


$$
\begin{aligned}
F j & =\sum A j i X i k \\
& =A j 1 X 1+A j 2 X 2+\ldots+\text { Ajp Xp }
\end{aligned}
$$

Where A's are known as standardised regression co-efficients or loading factors for the $j$ th factor and the ith item, Xik is the observed value of the ith item for case $k$. For example, the husband's domination factor is based on four items (or questions) as follows: whether important family decisions should be taken by the husband $(X 1)$; whether decisions about the number of children should also taken by the husband $(X 2)$; whether a woman can wear short-sleeved clothes without husband's permission $(X 3)$; and whether she can go to the movies $(X 4)$. The score for husband's domination in these four items is estimated as:

$$
\text { Husband's domination }=a 1 X 1+a 2 X 2+a 3 X 3+a 4 X 4
$$

Where $a 1=0.82, a 2=0.74, a 3=0.58$ and $a 4=0.53$ are the loading values (see Table 1) (weights) and $X$ 's are original values (responses). For example, for case

\begin{tabular}{|c|c|c|c|}
\hline Factors & Items & $\begin{array}{l}\text { Loading } \\
\text { Value }\end{array}$ & $\begin{array}{c}\text { Variance } \\
\text { Explaine } \\
\text { d }\end{array}$ \\
\hline \multirow{5}{*}{$\begin{array}{l}\text { Husband's } \\
\text { Domination }\end{array}$} & $\begin{array}{l}\text { All the important family decisions should be } \\
\text { taken by the husband }\end{array}$ & 0.82 & $\%$ \\
\hline & $\begin{array}{l}\text { Decisions about the number of children } \\
\text { should be taken by the husband }\end{array}$ & 0.74 & 23.3 \\
\hline & $\begin{array}{l}\text { Do you think you can wear short-sleeved } \\
\text { clothes without your husband's permission? }\end{array}$ & & \\
\hline & & 0.58 & \\
\hline & $\begin{array}{l}\text { Do you think you can go to the movies } \\
\text { without asking your husband? }\end{array}$ & 0.53 & \\
\hline \multirow[t]{3}{*}{ Role-egalitarian } & Help in cleaning house & 0.81 & \\
\hline & Help in food preparation & 0.74 & 10.2 \\
\hline & Help in children's preparation & 0.57 & \\
\hline Exposure to Mass & Having radio & 0.70 & 08.6 \\
\hline \multirow[t]{2}{*}{ Media } & Having TV & 0.65 & \\
\hline & Reading newspaper & 0.62 & \\
\hline \multirow[t]{2}{*}{ Role-segregation } & $\begin{array}{l}\text { A women should not ask her husband to help } \\
\text { in domestic chores }\end{array}$ & 0.74 & 08.1 \\
\hline & $\begin{array}{l}\text { Labour roles for men and women are } \\
\text { different }\end{array}$ & 0.63 & \\
\hline Total Variance ExI & $\mathrm{ed}=50.2 \%$ & & \\
\hline
\end{tabular}

Table 1

Principal Components Analysis of Role-relationships and Exposure Indicator 
10 the original responses for these items are $X 1=1$ (agree) and $X 2=1$ (agree), $X 3=$ 1 (agree) and $X 4=1$ (agree), respectively. Therefore, the score obtained by case 10 (respondent) on the issue of husband's domination is $0.82(1)+0.74(1)+0.58(1)+$ $0.53(1)=2.67$. In a similar fashion, the scores for each of the factors (indices) are calculated by taking into account responses of all respondents (cases) in the study. The weighted sum of scores would reflect more adequately the relative importance of each of the original variables constituting the index.

The chi-square test is employed to explore the relationships between predictor variables and the dependent variables. Multiple linear regression is also used to establish the relative importance of each of the predictor variables.

\section{FINDINGS OF THE STUDY}

The classification of questions on 'Role-relationships and Exposure' as indicators of the principal (main) factors identified by the PCA is presented in Table 1. The items 'important family decision', 'decision about the number of children', 'to go to the movies', and 'to wear short-sleeved clothes' indicate their correlation with the factor of husband's domination. The four factors named, Husband's domination, Role-egalitarian, Exposure to the mass media and Role-segregation, contributes 50.2 percent of the total variance in the four-factor model of 'Role-relationship and Exposure' (Table 1). The husband's domination index is the most important factor in the 'Role-relationships and Exposure' model because it contributes about 23 percent of the total variance. The other three factors almost contribute equal variance in the model, indicating their equal importance for explanation.

Before presenting the results of the multivariate (multiple linear regression) analysis, the association of socio-economic, demographic, and index variables with the contraceptive and fertility behaviour has been evaluated at bivariate level. For the purposes of a bivariate analysis, the distribution of scores of predictor variables is classified into three categories (low, medium, and high) indicating the direction of movement from traditional to modern orientation. The pattern of distribution of score is examined before dividing the scores into categories. It is seen that scores are fairly evenly distributed. The advantage of the equal sub-division approach is that it fairly well represents the original responses, and that is difficult to achieve in the cumulative approach. It is important to mention here that the collapsing procedure is used for a bivariate analysis, and not for multivariate analysis, of index variables. In the multiple linear regression analysis, the original scores are used.

\section{Bivariate Analysis}

\section{The 'Husband's Domination' Factor}

Husband's domination in family and non-family decisions emerges as an important factor having an implication for women's contraceptive use (Table 2). The 
Table 2

Percentage Distribution of IN Scale Values and User's and Non-users, by Socio-economic and Demographic Variables

\begin{tabular}{|c|c|c|c|c|c|c|}
\hline \multirow[b]{3}{*}{ Variables } & \multirow{3}{*}{$\begin{array}{c}\text { Users } \\
\%\end{array}$} & \multirow{3}{*}{$\begin{array}{c}\text { Non-users } \\
\%\end{array}$} & \multicolumn{2}{|c|}{ Family Bias } & \multicolumn{2}{|c|}{ (Coombs' IN Score) } \\
\hline & & & $1-4$ & 5 & $6-7$ & \\
\hline & & & Small + Medium & Large & Very Large & Total \\
\hline \multicolumn{7}{|c|}{ Woman's Education } \\
\hline $0-4$ & 30.3 & 48.0 & 9.0 & 19.7 & 71.3 & 457 \\
\hline $5-9$ & 19.8 & 30.5 & 14.7 & 25.6 & 59.7 & 293 \\
\hline $10-16$ & 50.0 & 21.4 & 37.1 & 30.9 & 32.0 & 350 \\
\hline Total & 400 & 700 & 214 & 273 & 613 & 1100 \\
\hline Mean & 7.6 & 5.1 & - & - & - & 6.0 \\
\hline Sig. Level & \multicolumn{2}{|c|}{0.01} & \multicolumn{4}{|c|}{0.01} \\
\hline \multicolumn{7}{|c|}{ Husband's Education } \\
\hline $0-9$ & 33.8 & 49.9 & 10.7 & 19.4 & 69.8 & 484 \\
\hline $10-13$ & 30.3 & 30.7 & 14.9 & 28.0 & 57.1 & 336 \\
\hline $14-16$ & 36.0 & 19.4 & 40.0 & 30.4 & 29.6 & 280 \\
\hline Total & 400 & 700 & 214 & 273 & 613 & 1100 \\
\hline Mean Schooling & 9.8 & 7.96 & - & - & - & 8.6 \\
\hline Sig. Level & \multicolumn{2}{|c|}{0.01} & \multicolumn{4}{|c|}{0.01} \\
\hline \multicolumn{7}{|c|}{ Occupation of the Husband } \\
\hline Salaried Worker & 45.5 & 55.6 & 16.1 & 25.2 & 58.7 & 571 \\
\hline Self Employed & 54.5 & 44.4 & 23.1 & 24.4 & 52.6 & 529 \\
\hline Total & 400 & 700 & 214 & 273 & 613 & 1100 \\
\hline Sig. Level & \multicolumn{2}{|c|}{0.01} & \multicolumn{4}{|c|}{0.05} \\
\hline \multicolumn{7}{|l|}{ Family Income } \\
\hline Less than 24000 & 31.4 & 28.4 & 14.9 & 24.1 & 61.0 & 323 \\
\hline $240001-50000$ & 41.0 & 46.3 & 19.6 & 25.2 & 55.3 & 485 \\
\hline $50000+$ & 27.6 & 25.3 & 24.8 & 24.8 & 50.3 & 286 \\
\hline Total & 398 & 696 & 214 & 271 & 609 & 1094 \\
\hline Sig. Level & \multicolumn{2}{|c|}{0.23501} & \multicolumn{4}{|c|}{0.05} \\
\hline \multicolumn{7}{|l|}{ Age at Marriage } \\
\hline $14-20$ & 59.8 & 78.9 & 13.9 & 22.6 & 63.5 & 791 \\
\hline $21-25$ & 35.5 & 17.9 & 33.3 & 29.6 & 37.1 & 267 \\
\hline $26-33$ & 4.8 & 3.3 & 35.7 & 35.7 & 28.6 & 42 \\
\hline Total & 400 & 700 & 214 & 273 & 613 & 1100 \\
\hline Mean Age & 20.2 & 19.1 & - & - & - & 19.5 \\
\hline Sig. Level & \multicolumn{2}{|c|}{0.01} & \multicolumn{4}{|c|}{0.01} \\
\hline
\end{tabular}


Table 2-(Continued)

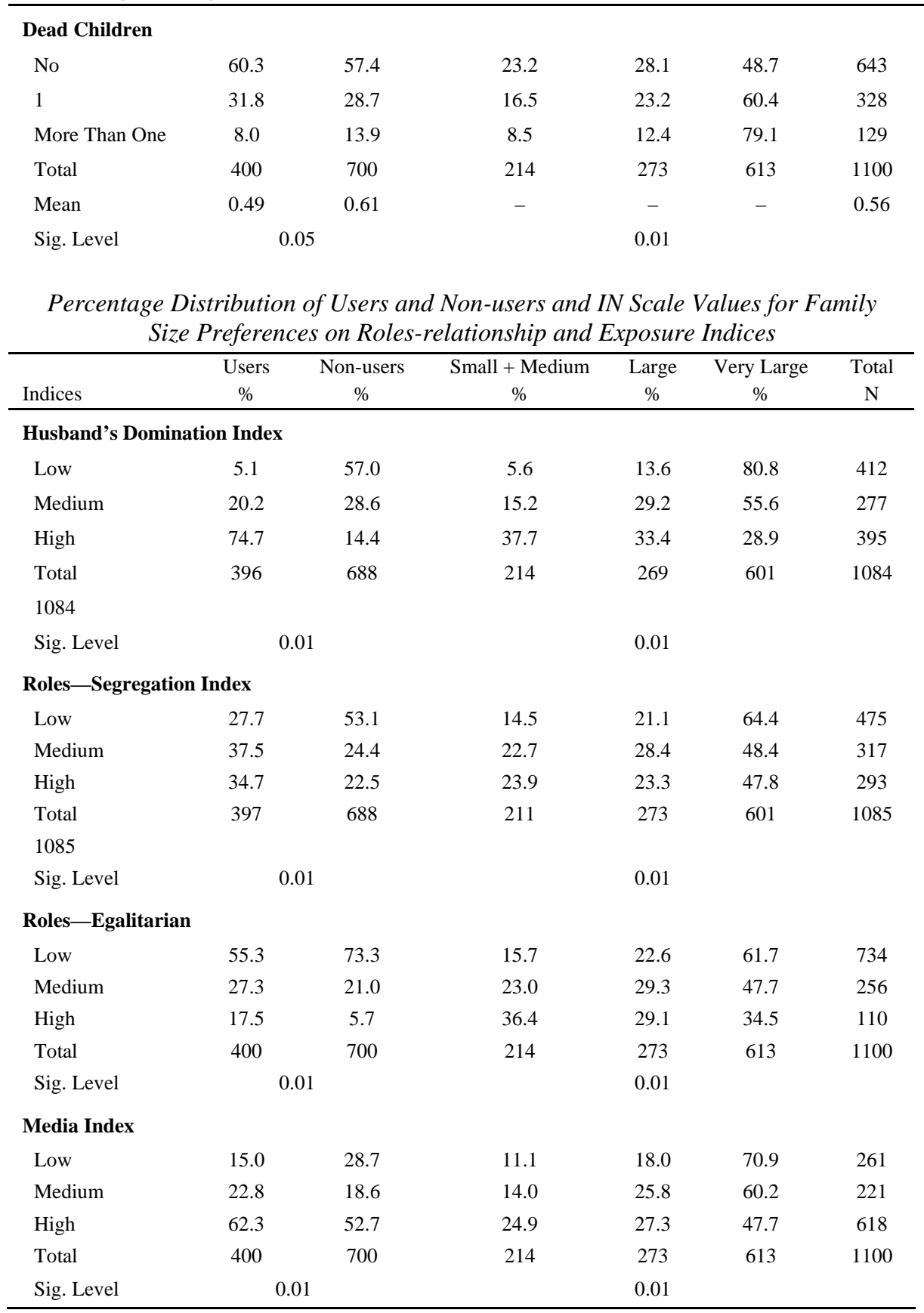


score distribution indicates that contraceptive users were more permissive with their husbands than non-users. The relationship between husband and wife has a direct association with the scores achieved by the respondents. The majority of users (75 percent) obtained high scores while only about 14 percent of the non-users were able to obtain the same score. The husband's domination index is also associated with fertility preferences. The number of women who obtained a low score (traditional in their outlook) and preferred very large families (IN 6-7) (81 percent) was considerably higher than that of women who obtained high scores and had the same fertility goals (29 percent).

The qualitative findings also confirm that husband's authority plays a decisive role in fertility decision-making. The exercise of traditional authority by the husband is reflected in the domination of husband in decision-making on major family and non-family matters. These include family decisions (children's marriage, the number of children) and financial decisions (purchase and sale of property). The general impression that emerges from the group discussions with respondents is that husbands retain the authority to make decisions on major issues. A close examination of the participants' views on the decision-making process indicates that wives have little control over family and non-family matters. Participants believe that husbands make unilateral decisions and wives are often helpless because they have no influence.

Despite the husbands' domination, the majority of contraceptive-using respondents from both cities express the view that husband and wife should jointly make decisions about financial and family matters.

The non-users of contraception express the view that although woman should participate in these decisions, the final decision should be taken by the husband, considering him to have more wisdom in such matters. The non-contraceptive-using participants accept the domination of the husband by saying that the husband is the master of the house and he has the final authority.

Non-users further state that a woman is bound to be submissive to her husband and bound to obey his orders because she is economically and socially dependent on the husband. They also point out that a young girl is socialised so that she should be submissive to her parents before marriage and to the husband and the parents-in-law after marriage. Participants' views are an indication of the husband's strong domination in family and non-family matters in Pakistan:

"Husband's behaviour is like a dictator's behaviour. He does what he desires. The wife is bound to accept and obey him because he is a bread-earner. A husband does not want to listen [to] her wife. If a woman has strength and power in her decision-making, then she could not bear so many children because she does not want to spoil her and 
the children's health". (Statement by a non-contraceptive-user in Faisalabad, illiterate age 38, with 6 living children.)

"It is better to leave all these matters with the husband, who has good experience of these matters. A woman's real job is to look after the children and husband. Therefore, she should be an expert in these affairs to make her marital life more stable". (Statement by a noncontraceptive-user in Lahore, age 32, with 6 years of schooling and 4 living children.)

\section{The 'Role-segregation’ Factor}

The second dimension to assess the influence of the husband and wife relationship on fertility and contraceptive behaviour is role-segregation. 35 percent of users as opposed to 23 percent of non-users have obtained a high score on the rolesegregation index variable (Table 2). Analysis also examines the influence of the role-segregation index on fertility behaviour. Women who preferred a very large family and have a low score (64 percent) are considerably higher than women who had the same fertility preference and have a high score on the index variable (48 percent). It has emerged that higher scores on index variables are associated with a weaker desire for a large family. It is also worth mentioning that respondents who have obtained a high score on the index variables of role-segregation were of the opinion that men's roles were very different from women's roles.

The focus group discussions with the respondents reinforce the finding that men are still expected to be the bread-winners and women to be the home-makers in the urban environment of Pakistan. The majority of participants express the view that domestic roles are women's primary roles and perceived as part of their obligations. Although domestic roles are not devalued by the husbands or by the Pakistani society, yet the husband's role as bread-winner is considered superior to wife's role, which is treated as subservient. Despite such traditional roles definition, most contraceptive users explain that their husbands have liberal and cooperative attitudes. A few respondents expressed the inappropriateness of asking for help around the house because the husband's prime role is as bread-winner. The following statement by a contraceptive-using respondent explains well the extent and nature of the husband-wife relationship.

"My husband frequently helps me in cooking and cleaning the house. When I am busy in other work, he prepares tea. Sometimes he irons not only his clothes but mine and those of the children [also]. If the children make a noise in the house, he keeps children outside the house”. (Statement by a user of contraception, 28 years of age, with 8 years of schooling and 3 living children.) 
Most non-contraceptive users (with the exception of a few who had more than eight years of schooling) suggest that it goes against the husband's honour and respect to ask him to help around the house. It conflicts with the image of manliness, and also it looks somewhat strange when the husband does house work, especially cooking, cleaning, and washing. The participants consider that a man and a woman have distinctive labour roles. Man is primarily responsible for bread-earning and woman's duties are looking after the children and the husband. A participant from Faisalabad said that

"It looks very strange when husband performs house work. A woman's responsibility is looking after the children and a husband's function is to fulfil the basic necessities of everyday life". (Statement by a noncontraceptive-user, age 30, with 4 years of schooling and 5 living children.)

Some non-users' views on the issue clearly reinforce the picture of a strong husband domination in Pakistan. In the society, a husband's help in the household help is considered a social stigma. Such a husband is considered a 'run-murid' (literally, follower of his wife) and is not respected by the peers and parents. Participants have expressed the view that self-actualisation lies in fulfilling their traditional roles as wives and mothers. A firm commitment and loyalty to their husbands helps wives to gain greater respect and involvement in family matters. One non-user from Lahore states:

"Men think that performance of the house chores is the duty of women. They feel insulted to help around the house. They quarrel when wives ask for help and say: If you want to live peacefully, live under my domination. You have to obey me in every respect, otherwise there is no place for you in the house'. A woman is bound to accept her husband's domination because man's role in the society is important". (Statement by a non-contraceptive-user, age 34, with no schooling and 5 children.)

\section{The 'Role-egalitarian’ Factor}

55 percent of contraceptive-using participants as compared to 73 percent of non-users have obtained low scores on the role-egalitarian index variable (Table 2). Egalitarian roles also affect fertility behaviour. Women who preferred a very large family and have a high score on the role-egalitarian index variable are lower (35 percent) than women who had the same preference for families and have a low score on the index variable (62 percent). The negative relationship between egalitarian 
roles and fertility behaviour further confirms that the higher the score on the egalitarian index scale, the lower the preference for large families.

From the focus group discussion the general impression that emerged was that women were not expected to be overtly aggressive or dominant or influential over their husbands because it was considered to reflect negatively upon both themselves and their husbands. It also emerged from the discussion that woman's freedom to move outside the home was related to dishonour of the husband and the family. The users had less restriction than the non-users. The users emphasised that it really is a matter of confidence, if the husband is confident that his wife will secure and protect his honour, then he will have no objection and will not prevent her going outside the home. One respondent (user) from Faisalabad said:

"Who will get permission again and again? If there is nothing for cooking at home and a woman is waiting for her husband's arrival from his job, then it is very difficult to run the home business." (Statement by a participant, age 29, with 10 years of schooling and 2 children.)

Most non-users (with the expectation of a few who had some years of schooling) expressed that they are helpless in these matters. Prior permission is compulsory to go outside for shopping. They also expressed that it is also moral and social responsibility of the wife to ask for permission because the social environment does not support the idea of free movement of woman. Slightly careless steps taken by the wife would be very dangerous for her future life. They further said that husband is known as 'Majazy Khuda' (de jure deity) of the wife. Therefore the protection of his respect and honour is the prime responsibility of a woman.

\section{The 'Media Exposure' Factor}

Users had slightly higher level of exposure to the mass media than non-users. 15 percent of users as compared to 29 percent non-users gained a low score. On the other hand, 62 percent of users as compared to 53 percent of non-users gained a high score on the index variable 'exposure to mass media' (Table 2). Exposure to mass media has an implication for fertility behaviour. Women who preferred very large families and had low score (71 percent) were more numerous than women who had the same preference for family size and had a high score (48 percent). It indicates that greater exposure to the mass media is associated with a weaker desire for large families.

\section{Summary of the Bivariate Analysis}

The bivariate analysis clearly demonstrates that socio-economic and demographic variables in terms of husband's and wife's education, husband's 
occupation, age at marriage, and number of children dead are associated with contraceptive use and fertility behaviour (Table 2). Different aspects of husband and wife relationships, in terms of husband's domination in familial and non-familial activities, segregation and egalitarian roles, and exposure to mass media, are associated with contraceptive use and fertility preferences.

It is clear from the bivariate analysis that many socio-economic, demographic, and cultural variables are associated with contraceptive use and fertility behaviour. During bivariate analysis, the effects of some factors are confounded with the effects of other factors. In order to find the real and net effect of each of the predictor variables in explaining the behaviour of the dependent variable, the multiple regression model was employed.

\section{Multiple Regression Analysis}

Before deciding to use multiple linear regression, it is necessary to examine whether the data meets all the assumptions required for the application of the technique. The assumptions are that each group must be from a multivariate normal population, and the population variance-covariance matrix for all groups must be equal. There are several ways to verify these assumptions required for the technique, among them scatter plots of residuals against the predicted values is a convenient approach to test the assumption of linearity and homogeneity of variances. The scatter plots of different socio-demographic and attitudinal variables with residual values did not show any relationship indicating that the assumption of linearity and homogeneity of variances seemed to be satisfied. A histogram was also constructed to show whether the groups come from a multivariate normal population. The distribution of residuals presented in the form of a histogram confirmed that the data was from a multivariate normal population. It is also worth mentioning here that slight deviation from the assumption does not affect the results because it is unreasonable to expect the observed residuals to be exactly normal. Some deviation is expected because of sampling variation [Norusis (1990)], and also the overall Ftest for significance is relatively robust against a departure from normality and against inequality of the covariance matrices, at least for a large sample.

As mentioned earlier, multiple regression is used to establish the relative importance of each of the background and cultural variables in terms of explained variation in the dependent variables. The standardised partial regression co-efficients (beta's) are used to estimate the relative significance of each of the predictor variables, and the multiple co-efficient of determination $(R 2)$ is used to measure how well the independent variables explained the dependent variable.

Step-wise regression analysis is performed. All background variables (socioeconomic and demographic variables) are entered one by one at first to assess their individual influence on contraceptive use. A built-up procedure for the investigation 
of the influence of cultural index variables is used. Index variables of cultural dimension are entered one by one.

The results of multiple linear regression analysis presented in Table 3 show that none of the background variables such as husband's education and occupation, age at marriage, and child mortality, except woman's education, could contribute the variation in the outcome variable in the full regression model. Husband's education produced a beta coefficient 0.17 significant at 0.01 and contributed 2.7 percent variation in the dependent variable. It is interesting to mention that husband's education could not maintain its positive level of influence on contraceptive use when wife's education was introduced to the model. The explanatory power of husband's education completely disappeared when woman's education was included in the second step. Women's education provided an explained variance of 6.7 percent with a beta coefficient of 0.27 significant at 0.01 . It is worth mentioning that occupation of the husband, woman's age at marriage, and child mortality produced almost zero beta coefficients and accounted for explained variance of 0.2 percent in the outcome variable, indicating that these three variables, along with family income (which is not included in the regression model because it was not associated with contraceptive use at the bivariate level), exert no influence on contraceptive behaviour.

In the role-relationships and exposure category, the first index variable added in the regression equation is exposure to the mass media in the 6th step. With the entrance of the media exposure variable, the effect of women's education which was very consistent up to the 5th step is moderated and the beta coefficient for women's education reduced from 0.27 to 0.21 , still significant at 0.01 . The media exposure index variable produced a beta coefficient of 0.16 , significant at 0.01 and explained 1.6 percent variance. The explanatory power of the media exposure indicator was slightly reduced (Beta value reduced from 0.16 to 0.14 ) when the index variable roleegalitarian was introduced in the model. The index variable role-egalitarian accounted for changes in the contraceptive use of about 3.7 percent and with a beta value of 0.20 significant at 0.01 . The role-segregation index variable produced a beta coefficient of 0.15 significant at 0.01 and accounted for a two percentage point variance in $R 2$ by increasing $R 2$ from 12.2 percent to 14.2 percent. The index variable of husband's domination in the regression equation produced very striking results. The husband's domination index variable produced the highest beta coefficient, i.e., 0.60 significant at 0.01 , and accounted for a massive increase in $R 2$ from 14.2 to 41.8 . With the addition of that variable in the regression equation, women's education, which was maintaining its quite substantial effect up to the 8th step, moderated and the effect of media exposure completely disappeared by producing insignificant beta coefficient. A single index variable, husband's domination, produced 27.6 percentage points of variation in the outcome variable. 
Table 3

Standardised Partial Regression Coefficients (Beta's) for Contraceptive

Use Regressed on Background Attitudinal Characteristics, Pakistan, 1991

\begin{tabular}{|c|c|c|c|c|c|c|c|c|c|c|}
\hline & 1 & 2 & 3 & 4 & 5 & 6 & 7 & 8 & 9 & 10 \\
\hline \multicolumn{11}{|l|}{$\begin{array}{l}\text { Socio-economic and } \\
\text { Demographic }\end{array}$} \\
\hline 1-HUSEDU & $.17^{* *}$ & ns & ns & ns & ns & ns & ns & $-.09 *$ & $-.08 * *$ & ns \\
\hline 2-WOEDU & - & $.27 * *$ & $.29 * *$ & $.27 * *$ & $.27^{* *}$ & $.22 * *$ & $.20 * *$ & $.19 * *$ & $.16^{* *}$ & $.15^{* *}$ \\
\hline 3-OCCUPATION & - & - & ns & ns & ns & ns & ns & ns & ns & ns \\
\hline 4-FAMILY INCOME & - & - & - & ns & ns & ns & ns & ns & ns & ns \\
\hline 5-AGE AT MARRIAGE & - & - & - & - & ns & ns & ns & ns & ns & ns \\
\hline 6-CHILDIED & - & - & - & - & - & ns & ns & ns & ns & ns \\
\hline \multicolumn{11}{|l|}{$\begin{array}{l}\text { Role-relationship and } \\
\text { Exposure Indicator }\end{array}$} \\
\hline 7-MEDIA EXPOSURE & - & - & - & - & - & - & $.16^{* *}$ & $.14^{* *}$ & $.13^{* *}$ & ns \\
\hline 8-EGALITARIAN & - & - & - & - & - & - & - & $.20 * *$ & $.14^{* *}$ & $.07 * *$ \\
\hline 9-SEGREGATION & - & - & - & - & - & - & - & - & $.15^{* *}$ & $.12^{* *}$ \\
\hline $\begin{array}{l}\text { 10-HUSBAND’S } \\
\text { DOMINATION }\end{array}$ & - & - & - & - & - & - & - & - & - & $.60 * *$ \\
\hline$R 2$ & 2.7 & 6.7 & 6.8 & 6.9 & 6.9 & 6.9 & 8.5 & 12.2 & 14.2 & 41.8 \\
\hline
\end{tabular}

* Significant at the .05 level (one tail).

** Significant at the .01 level (one tail). 
The husband's domination index variable appeared as the most powerful predictor variable in determining contraceptive behaviour. It emerges from these findings that husband and wife relationships are the emerging forces influencing the contraceptive decision-making process.

Coomb's IN Scale, a measure for family size preference, is also used as a dependent variable in this study. Husband's education produced very striking results (Table 4) when it was entered in the regression model in the first step. Husband's education produced beta coefficient of -0.33 significant at 0.01 and accounted for about 10 percent of the explained variance. The negative sign of the beta coefficient indicates that there is an inverse relationship between the level of education and the fertility preference. The higher the level of education, the lower the preference for large families. When women's education was added in the model, the explanatory power of husband's education was decreased and the beta coefficient for husband's education reduced from -0.33 to -0.16 , still significant at 0.01 . Women's education produced a beta coefficient of -0.26 significant at 0.01 and contributed about 4 percentage points variance in the fertility preference. In the third and fourth steps, when family income and husband occupation respectively were included in the regression equation, the beta coefficients for husband's education and women's education remained the same. Family income and husband's occupation offered no explanation in the behaviour of the outcome variables by producing zero beta coefficients, and no change in $R 2$. Age at marriage produced moderate beta coefficient of -0.10 and $R 2$ increased from 14.6 to 15.1. The negative sign indicates the inverse relationship between age at marriage and fertility preferences. The higher the age at marriage, the lower the preferences for large families. Child mortality offered a poor explanation in the behaviour of the dependent variable by producing a beta coefficient of +0.06 significant at .05 . Up to the 6th step, husband's education, women's education, and age at marriage were the effective forces in determining fertility behaviour, with beta coefficients $-0.13,-0.22$, and -0.09 respectively, all significant at 0.01 .

When the index variable 'media exposure' was entered in the regression equation, the explanatory power of husband and wife's education was reduced. Beta coefficients for husband's education reduced from -0.13 to -0.09 and the beta value for women's education reduced from -0.21 to -0.17 . The media exposure index variable produced a beta coefficient of -0.15 and accounted for an explained variance of 1.2 percent. When the roles-egalitarian and roles-segregation index variables were included in the regression model at the 8th and 9th steps, the effect of husband's education, women's education, and age at marriage slightly moderated (Table 4). These two index variables produced the same value of beta coefficients, i.e., -0.13 , and offered three percentage points of variance in the family size preference. The 9th step proved crucial for many variables which were already in the 
Table 4

Standardised Partial Regression Coefficients (Beta's) for Family Size Preferences Regressed on Background Attitudinal Characteristics, Pakistan, 1991

\begin{tabular}{|c|c|c|c|c|c|c|c|c|c|c|}
\hline & 1 & 2 & 3 & 4 & 5 & 6 & 7 & 8 & 9 & 10 \\
\hline \multicolumn{11}{|l|}{$\begin{array}{l}\text { Socio-economic and } \\
\text { Demographic }\end{array}$} \\
\hline 1-HUSEDU & $.33 * *$ & $.16^{* *}$ & $.16^{* *}$ & $.15^{* *}$ & $.14^{* *}$ & $.13^{* *}$ & $.09 *$ & $.08 *$ & $.08 *$ & ns \\
\hline 2-WOEDU & - & $.26^{* *}$ & $.26 * *$ & $.26 * *$ & $.24 * *$ & $.22 * *$ & $.17^{* *}$ & $.16^{* *}$ & $.15^{* *}$ & $.12 * *$ \\
\hline 3-OCCUPATION & - & - & ns & ns & ns & ns & ns & ns & ns & ns \\
\hline 4-FAMILY INCOME & - & - & - & ns & ns & ns & ns & ns & ns & ns \\
\hline 5-AGE AT MARRIAGE & - & - & - & - & $.10 * *$ & $.09 * *$ & $.08 *$ & $.08 *$ & $.07 * *$ & ns \\
\hline 6-CHILDIED & - & - & - & - & - & $-.06^{*}$ & ns & ns & ns & ns \\
\hline \multicolumn{11}{|l|}{$\begin{array}{l}\text { Role-relationship and } \\
\text { Exposure Indicator }\end{array}$} \\
\hline 7-MEDIA EXPOSURE & - & - & - & - & - & - & $.15^{* *}$ & $.14^{* *}$ & $.14 * *$ & $.08^{*}$ \\
\hline 8-EGALITARIAN & - & - & - & - & - & - & - & $.13^{* *}$ & $.11^{* *}$ & ns \\
\hline 9-SEGREGATION & - & - & - & - & - & - & - & - & $.13 * *$ & $.12^{* *}$ \\
\hline 10-HUSBAND’S DOMINATION & - & - & - & - & - & - & - & - & - & $.33^{* *}$ \\
\hline$R 2$ & 9.8 & 14.1 & 14.1 & 14.2 & 15.1 & 15.4 & 16.8 & 18.2 & 19.8 & 27.9 \\
\hline
\end{tabular}

Note: All beta co-efficients bear negative sign except 'how many children died?'

* Significant at the.05 level (one tail).

** Significant at the .01 level (one tail).

HUSEDU : Husband's education.

WOEDU : Woman's education.

HMCHD : How many children died? 
model when the index variable 'husband's domination' was added to the model. With the entrance of the husband's domination index variable, the explanatory power of husband's education, age at marriage, and roles egalitarian diminished. The significant beta coefficients for these variables turned insignificant, indicating the importance of the husband's domination variable. The husband's domination index variable produced a beta coefficient of -0.33 and accounted for eight percentage points of variance in fertility behaviour. It emerges from the findings that women's education, media exposure, roles segregation, and husband's domination are important dimensions in determining fertility behaviour with beta coefficients -0.12 , $0.08,-0.12$ and -0.33 respectively, the second one significant at .05 and the others two significant at 0.01 . The most powerful predictor variable in the role-relationship (husband and wife) model which exerts an independent and strong influence on family size preference is husband's domination, with a beta coefficient of -0.33 . A similar relationship between the husband's domination index variable and contraceptive use has been observed in the previous regression model.

\section{DISCUSSION}

The Government of Pakistan is aware of and concerned about the country's rapid population growth and its effect as an impediment to the development of other social and economic factors [Sathar (1993)]. There has been only limited progress in reducing fertility since the inception of the family planning programme in the country. This study has sought to contribute towards the understanding of factors which can influence contraceptive use and fertility behaviour in urban Pakistan.

There has been considerable debate within population studies concerning the relative importance of structural, socio-cultural, and programme-related factors in accounting for the declines in fertility. The findings of this study lend strong support to socio-cultural, rather than more structural, economic and mortality-related factors. For instance, there was a lack of association between such variables as husband's occupation, family income, and child mortality with contraceptive use and fertility behaviour in this sample of urban areas.

In contrast to economic factors, the survey indicated a strong association between the set of variables related to women's status and the contraceptive and fertility behaviour. It is important to note that husband's education itself was not found to be a significant explanatory variable after other gender-related factors were introduced into the regression model. The qualitative data from focus groups discussion helped to further elaborate upon the ways in which these gender, power, and role factors shaped the fertility decision-making process and contraceptive use.

The importance of gender-related factors in understanding fertility-regulating behaviour is now well-recognised [Backman (1983)]. The particular contribution of 
this analysis has been its disaggregation of different components of the gender construction of husband-wife relations and their bearing upon contraceptive use and fertility. A number of gender-related items in the interview schedule were found to correlate in terms of three basic underlying components (using principal component analysis): (i) the 'husbands domination' factor pertaining to the freedom of the wife to engage in various activities outside the household independently of her husband; (ii) the 'role-segregation' factor pertaining to how strongly the husband and wife adhered to traditional gender roles within the household; and (iii) the 'egalitarian' factor pertaining to how far the husband and wife relationship is considered to improve a measure of equality on a more general level. A comparative analysis of contraceptive-using and non-using women revealed that the 'husband's domination' factor was the most important of the gender-related factors in explaining fertilityregulating behaviour, followed in turn by the 'role-segregation' and 'egalitarian' factors along with woman's education.

Interpretation of the implications of this analysis for the family planning programme promotion in urban Pakistan can be undertaken on a number of levels. First, (as noted above) the analysis is consistent with socio-cultural explanations of fertility declined [Cleland (1985)]. Secondly, within the whole complex of relevant socio-cultural factors, the nature of the husband-wife relationships and woman's education are probably the most important factors (above, for instance, husband's education and media exposure in this study) in facilitating increase in contraceptive prevalence. It is acknowledged that the gender construction of conjugal relations comprises a whole which, in turn, is linked to a broad 'traditional'-modern' continuum of social change. Thirdly, the analysis identified particular aspects of husband-wife relations which have an especial bearing upon fertility-regulating behaviour.

At this point, it is useful to express the interpretation of the 'husband's domination' factor in both positive and negative terms. The degree to which the wife felt free to engage in a range of activities outside the household without her husband's consent and her participation in important family decisions is strongly associated with the use of contraception and fertility preferences (Coombs IN's Scale). The 'husband's domination' factor could alternatively be termed as the 'domination' factor, whereby the degree of husband's domination or control of his wife's freedom even to engage in family-limited activities outside the home is strongly associated with non-use of contraception. The husband's domination is the most striking indicator of the conjugal relations. Its greater explanatory power also presumably derives from its being more behaviourally-specific [Eiser (1986)] than the more general 'egalitarian' factor. The analysis highlights the value of selecting variables in population research which focus on specific behaviour rather than abstract concepts. 
In Pakistan, the primary emphasis of the fertility-related component of population policy (of which family planning programmes are the main tool) is demographic-developmental. Internationally, there is a growing interest in the advocacy for family planning programmes which also stress maternal and child health and women's status rationales [Ford (1993)]. The crucial questions of how these different rationales converge or conflict largely depends upon the specific ways in which family planning programmes are designed and implemented. The findings of this study of urban Pakistan strongly indicate that in the attainment of demographic-developmental objectives of the population policy, the women's status issue is not incidental, but essential. This is not to argue that improvements in women's status need to be pursued only for population policy purposes; clearly, they comprise a crucial social development goal in their own right. Rather, the conclusion derived from this research is that the 'parallel' pursuit of policies to enhance women's status in Pakistan should have a critical facilitating effect on progress towards reducing fertility. As well as general, specific and carefully articulated policies integrating women's status and population issues are a pressing need; they will address gender issues in the refinement and implementation of the family planning programme in Pakistan [Dixon-Mueller (1993)]. It is further suggested that the emphasis and focus of gender concerns in reproductive health programmes in the Pakistan setting can be more gainfully addressed by enhancing freedom in the behavioural aspects (related, for instance, to the 'husband's domination' factor in the foregoing analysis) than in the more abstract concepts of equality.

\section{REFERENCES}

Alam, I., and J. Cleland (1991) Illustrative Analysis: Recent Fertility Trends in Sri Lanka. (WFS Scientific Report No. 25.)

Bongaarts, J. A. (1978) Framework for Analysis of the Proximate Determinants of Fertility. Population and Development Review 4:1 105-132.

Becker, G. S. (1981) A Treatise on the Family. Harvard: Harvard University Press.

Beckman, L. (1983) Communication, Power, and the Influence of Social Networks in Couple Decisions on Fertility. In R. A. Bulatao and R. D. Lee (eds) Determinants of Fertility in Developing Countries 2. New York: Academic Press. 415-443.

Coombs, L. C. (1976) Are Cross-cultural Preferences Comparisons Possible? A Measurement-Theoretic Approach. Liege, Belgium. (IUSSP Paper No. 5.)

Coombs, L. C., and T. H. Sun (1973) Family Composition Preferences in a Developing Culture: The Case of Taiwan. Population Studies 31: 43-64.

Cleland, J. (1985) Marital Fertility Decline in Developing Countries. In J. Cleland and J. Hobcraft (eds) Reproductive Change in Developing Countries. Insight from the World Fertility Survey. Oxford: Oxford University Press. 223-252. 
Dixon-Mueller, R. (1993) The Sexuality Connection in Reproductive Health. Studies in Family Planning 24: 269-282.

Easterlin, A. R. (1983) Modernisation and Fertility: A Critical Essay. In R. A. Bulatao and J. Bongaart (eds) Determinants of Fertility in Developing Countries 2. New York: Academic Press. 563-586.

Eiser, J. R. (1986) Social Psychology: Attitudes, Cognitive and Social Behaviour. Cambridge: Cambridge University Press.

Freedman, R. (1987) Fertility Determinants. In J. Cleland et al. (eds) In Collaboration with D. Whitellege The World Fertility Survey: An Assessment. Oxford: Oxford University Press. 773-795.

Ford, N. J. (1993) The Effect of Population Programmes Upon Quality of Life and Sustainable Development. (Cairo) Round Table on 'Population and Development Strategies'. University of Exeter, U.K. (Discussion Paper for UNFPA/ESCAP.)

Hashmi, S. S. (1991) Growth of Population and Social and Economic Development in Pakistan: An Occasion for Reassessment. Islamabad: National Institute of Population Studies. Population Welfare Programme.

Kirk, D. A. (1971) New Demographic Transition. National Academy of Science with Support of the Agency for International Development. Baltimore: Johns Hopkins Press for the National Academy of Sciences.

Knodel, J. E., N. C. Chamratrinthirong, and D. Nibhon (1982) Fertility in Thailand: Trends, Differentials and Proximate Determinants. Washington, D. C.

Knodel, J. E., N. Havanon, and A. Pramualratana (1984) Fertility Transitions in Thailand: A Qualitative Analysis. Population Development Review 10: 297345.

Lesthaeghe, R., and C. Wilson (1986) Modes of Production, Secularisation, and the Pace of the Fertility Decline in Western Europe, 1870-1930. In A. J. Coale and S. C. Watkins (ed) The Decline of Fertility in Europe. New Jersey: Princeton, Princeton University Press. 261-292.

Nachmias, S., and D. Nachmias (1981) Research Methods in the Social Sciences. New York: St. Martin's Press.

Nai Peng, T., and I. Abdurahman (1981) Factors Affecting Contraceptive Use in Peninsular Malaysia. (WFS Scientific Reports No. 23.)

Norusis, M. J. (1990) SPSS/PC+ Advanced Statistics 4.0 Manual. Chicago: SPSS Inc.

Oppong, C. (1982) Family Dtruvture and Women's Reproductive and Productive Roles: Some Conceptual and Methodology Issues. In A. Anker, M. Buvinic and N. Touseef (eds) Women Roles and Population Trends in Third World. Croom Helm, London. 133-150. 
Pakistan, Government of (1991) Pakistan Demographic and Health Survey. Islamabad: National Institute of Population Studies.

Pakistan, Government of (1992) Report of the Working Committee on Population Welfare Programme for Eight Five Year Plan, 1993-1998. Islamabad: Ministry of Population Welfare.

Pollack, R. J., and S. C. Watkins (1993) Culture and Economic Approaches to Fertility: Proper Marriage or Misalliance. Population and Development Review 19:3 467-496.

Ramu, G. N. (1988) Family Structure and Fertility: Emerging Patterns in an Indian City. London: Sage Publications.

Soeradji, B., and S. H. Hatmadji (1982) Contraceptive Use in Java-Bali: A Multivariate Analysis of the Determinants of Contraceptive Use. (WFS Scientific Report No. 24.)

Schearer, S. B. (1983) Monetary and Health Costs of Contraception. In R. A. Bulatao and R. D. Lee (eds) Determinants of Fertility in Developing Countries 2. New York: Academic Press. 89-150.

Shah, N. M. (1986) Introduction. In N. M. Shah (ed) Pakistani Women: A Socioeconomic and Demographic Profile. Islamabad: Pakistan Institute of Development Economics. 1-45.

Sathar, Z. A. (1993) The Much-awaited Fertility Decline in Pakistan: Wishful Thinking or Reality? International Family Planning Perspectives 19:4 142146.

Tietelbaum, M. S. (1975) Relevance of Demographic Transition Theory for Developing Countries. American Association for Advancement of Science and Population 174-179.

United Nations (1974) Report of the United Nations World Population Conference. A/Conf. 60/19. New York: United Nations.

World Bank (1991) World Development Report. The Changes of Development: World Development Indicators. New York: Oxford University Press. 